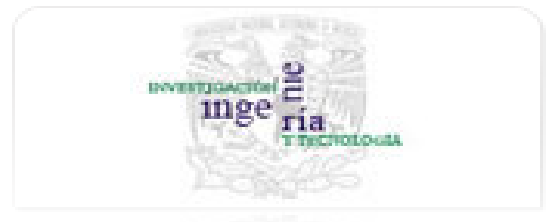

Ingeniería. Investigación y Tecnología

ISSN: $1405-7743$

iit.revista@gmail.com

Universidad Nacional Autónoma de México

México

Sánchez-Lara, B.; Sánchez-Guerrero, G.

Diagnostic Basic Elements for Quality Practices Implementation

Ingeniería. Investigación y Tecnología, vol. X, núm. 1, enero-marzo, 2009, pp. 1-7

Universidad Nacional Autónoma de México

Distrito Federal, México

Available in: http://www.redalyc.org/articulo.oa?id=40411427001

How to cite

- Complete issue

More information about this article

Journal's homepage in redalyc.org

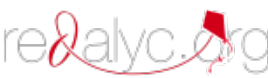

Scientific Information System Network of Scientific Journals from Latin America, the Caribbean, Spain and Portugal Non-profit academic project, developed under the open access initiative 
RIIT Vol.X. No.1. 2009 1-7, ISSN 1405-7743 FI-UNAM

(artículo arbitrado)

\title{
Diagnostic Basic Elements for Quality Practices Implementation
}

\section{Elementos de diagnóstico para la implantación de prácticas de calidad}

\author{
B. Sánchez-Lara \\ Posgrado en Ingeniería, Facultad de Ingeniería, \\ Universidad Nacional Autónoma de México. \\ E-mail:blara@servidor.unam.mx \\ G. Sánchez-Guerrero \\ Posgrado en Ingeniería, Facultad de Ingeniería, \\ Universidad Nacional Autónoma de México. \\ E-mail:gsg@servidor.unam.mx
}

(Recibido:febrero de 2006; aceptado: abril de 2008)

\begin{abstract}
This paper identifies the most relevant diagnostic elements that Mexican consultants use in order to know the current performance of micro, small and medium size enterprises (MSME) prior to a quality practice implementation and to estimate the probability of success of their intervention. In order to obtain the diagnostic basic elements we employed a web-based survey. In grouping of the diagnostic elements Howard and Associates integrated organizational diagnosis model, factor analysis and cluster analysis were used. Thirty four diagnostic basic elements and seven diagnostic categories were identified. We find about $90 \%$ of the consultants had made successful implementations in most of the times (75\% to 100\%) when using diagnostic elements.
\end{abstract}

Keywords: Diagnosis, diagnosticelements, MSME, quality practices, consultancy.

\section{Resumen}

Este artículo identifica los elementos de diagnóstico más relevantes que consultores mexicanos utilizan para conocer la situación de las micro, pequeñas y medianas empresas $(M P y M E)$ durante la fase previa a la implantación de una práctica de calidad y estima la probabilidad de éxito de su intervención. Para obtener los elementos de diagnóstico empleamos la metodología de la encuesta vía página web. En la agrupación de los elementos de diagnóstico se utilizó el Modelo de Diagnóstico Integral de Haward, el Análisis de Factores Principales y el Análisis de Conglomerados. Se identificaron 34 elementos básicos de diagnóstico y siete categorías de ellos. Se encontró que $90 \%$ de los consultores, al utilizar los elementos de diagnóstico, han logrado implementaciones exitosas entre 75 y 100\% de las veces.

Descriptores: Diagnóstico, elementos de diagnóstico, MPYME, prácticas de calidad, consultoría.

\section{Introduction}

The spread of the success of businesses based on quality practices implementation is wide; however, some work reports question their effectivity and their impact on quality performance. Some of the titles we have found are very illustrative in this respect: Is your TQM program successful? (Ahmadi \&
Helms, 1995), ISO 9000 certification benefits, reality or myth? (Dick, 2000), Does TQM impact on bottom line results? (Zairi et al., 1994), Is it spring or autumn for TQM? (Pitts, 1994), Does implementing an effective TQM program actually improve operating performance? (Hendricks \& Singhal, 1997), and The fallacy of universal best practices (Harrington, 1997). 
Reports show that many businesses think their efforts for quality improvement have not enhanced their ability to compete and that many quality practices need to be more focused in order to get better results and increase the rate of success in an implementation. This rate has been perceived as low (Harrington, 1997; Casadesús \& Giménez, 2000; Galperin \& Lituchy, 1999).

The above statements have motivated that researchers have attempted (1) to comprehend and rationalize the complexities of numerous quality ideas, concepts and theories, and (2) to fill gaps in the body of knowledge by developing new guides and procedures (Zain et al., 2001).

In particular, there seems to be a need to determine the underlying conditions that improve the possibilities of the implementation's success and to asses the real impact that implementation has over the businesses' performance (Bunney \& Dale, 1997; Easton \& Jarrell, 1998; Harrington, 1997; Hendricks \& Singhal, 1997; Flynn et al.,1995; Zairi et al., 1994, Mann \& Kehoe, 1994; Dayton, 2001; Taiwo, 2001).

On the first research line, namely that on ideas and concepts, Bunney \& Dale (1997), Easton \& Jarrell (1998) and Harrington (1997) have agreed that in order to enhance the quality practices implementation success, it is very important to have knowledge of the current performance on the organization. In this sense, Easton \& Jarrell (1998) have suggested the existence of enabling factors that would make quality practices effective in some organizations but ineffective in others. The decision to implement or not a quality practice should be based on managers' knowledge of these factors.

In considering that the diagnosis is the planning stage in which the organization's current performance has to be determined, it is very important the role of the consultant who is going to be responsible of the implementation.

This exploratory research attempts to find some preliminary answers to the following questions:

1) What are those elements used by Mexican consultants for the organizational diagnosis before implementing a quality practice? and

2) What is then the probability of success on this implementation when those elements were used in the diagnosis formulation?

In the Mexican consulting context, the present research takes relevance because the body of literature available related with implementing of quality practices is meager. Additionally, more of the literature is a collection of anecdotal evidence and author's personal prescription.

An important term used throughout this paper is the term "quality practices". This is a generic term which describes a distinguishable tool or method used for quality improvement.

\section{Diagnosis}

Diagnosis is the first fully operational phase of the consulting process. The purposes of diagnosis is to examine the problem faced by the client in detail and in depth, identify the factors and forces that are causing the problem, and prepare al information needed for deciding how to orient the work on the solution to the problem.

An additional purpose is to examine thoroughly significant relationships between the problem in question and the global objectives and performance results achieved by the client organization, and to ascertain the client's potential to make changes and resolve the problem effectively. Furthermore, in practical terms diagnosis is preparation for action (International Labour Office, 1986).

In practice it is often difficult or inappropriate to make a strict distinction and draw a line between the diagnosis and the action-planning phases of the consulting processes. It is not only that diagnosis lays down the bases for the work to follow. Frequently, diagnosis work will already identify and explore possible solutions.

Diagnosis requires a great deal of imagination and creativity in addition to experience in analysis business, management and human problems. Experience helps consultants to define what facts or dates are wanted. Experienced consultants apply the principle of selectivity. They appreciate that virtually unlimited amounts of factual information are available in any organization, but that an excessive amount of such information easily becomes unmanageable and can not be fully utilized in consultancy.

\section{Background}

MSME represent $99 \%$ of the current number of businesses in Mexico. They employ nearly the $65 \%$ of the work force and contribute with $40 \%$ of the GNP. Family businesses are $65 \%$ of the total MSME businesses (Secretaría de Economía, 1999). The expected life of 
this kind of businesses is very short since nearly $80 \%$ go to bankruptcy before the first year (NAFIN, 2004).

There are 641 consulting companies registered in México and more than 500 registered individual consultants. The second group forms the official list that the Mexican government uses to allocate consultancy for MSMEs. Individual consultants are included in the database of governmental programs for business development (CNEC, 2003).

\section{Survey design and application}

To answer the questions posed above we employed a web-based survey using a standardized questionnaire as a research instrument.

The questionnaire had two parts: the first focused to find out the consultants profile and the second focused towards actually answering the research questions.

The questionnaire was examined and validated by three groups of respondents. The first one was composed by advanced graduate students; the second by experienced faculty members with consulting experience and, the third was a small group of consultants, they were not included on the ones surveyed.

The survey response rate was compelled by sending a postal invitation letter. In some cases consultants asked for more background information on the research project.

The sampling frame was the federal government consultant's database. This database contains those registered individual consultants, from all over the country, who have been certificated to work with government on business development programs. The sample was integrated by certified consultants whose record showed they were involved in interventions to implement quality practices and that they had an e-mail address. The final sample for the study consisted of 201 consultants.

The questionnaire was applied through a web site designed for that purpose. According to Nesbary (2000) web surveys combine the accuracy of a written survey with the flexibility of an interview. The interviewee must enter data in the correct data location ensuring increased accuracy. Web surveys provide the added flexibility and power of database entry and analysis. Structured properly, web surveys responses may be entered and stored in database format. The data may be automatically coded and analyzed, saving a tremendous amount of time and effort on the part of the survey administrator.
Web surveys can also be relatively inexpensive. With web surveys and e-mail surveys, there are no mailing or long distance telephone costs. Further, coding and analysis costs may be kept to a minimum, if database tools are used to retrieve survey responses. In this research our costs were increased by the fact that the postal invitation letter was sent to each one of the consultants in the sample.

Response rate and response time are functions of the accuracy of the mail database being used by the survey administrator. If respondent addresses are accurate, the likelihood of the fast response time and a high response rate increases.

Web surveys have many important limitations. First, only those persons and organizations with Web access may complete the surveys. Second, it is argued that web surveys are likely not to capture responses form minorities and the poor. Another weakness of web surveys is security. Without password protection or other security scheme, any person happening across the web survey may respond to it.

This means that there may be no way of identifying the survey respondents. To limit the access to the web, in this research an individualized e-mail was sent to each consultant sample with a personalized hyperlink to the web asking them to answer the questionnaire. Personalization was made by building personal identification numbers (PIN) for each consultant surveyed. Once the consultant downloaded and answered the questionnaire he was asked to send it back by e-mail.

For grouping the diagnostic elements we used qualitative and quantitative methods. Qualitative grouping was based on Howard and Associates integrated organizational diagnosis model and a wide ranging set of items identified by the authors within the literature about diagnosis. Factor analysis and cluster analysis, through application of the SPSS package, were used for quantitative grouping.

\section{Data analysis}

Sixty five questionnaires, out of the 201 originally sent, were completed and got back. The response rate achieved was 32.3 percent; 418 different diagnostic elements were obtained from the questionnaires. Surveyed consultants used 7.4 elements in the average. Qualitative grouping shows that those 418 diagnostic elements could be grouped into 34 different diagnostic basic elements; these are shown in table 1. 
Table 1. Diagnostic basic elements for quality practices implementation

\begin{tabular}{ll} 
Layout and physical conditions & Capacity of response (resources and attitudes) \\
Quality systems e.g. ISO 9000 series & Management commitment \\
Production techniques e.g. Just-in-time & Leadership styles \\
Technological level (processes automation) & Employee relations \\
Productivity e.g. level of rejection, waste, process time & Organizational culture (change resistance and maturity) \\
Quality improvement activities & Competences \\
Experience in implementation of quality practices & Motivation e.g. turnover, absenteeism, job satisfaction \\
Training in quality practices & Form of business ownership \\
Strategic planning practices & Financial performance e.g. profits, net income \\
Management practices & Quality performance measures \\
Vision and mission & Sales and inventory \\
Goals and objectives & Identification of main clients \\
Processes documentation (existence) & Identification of main suppliers \\
Processes documentation (availability) & Client satisfaction \\
Processes documentation (formality) & Value added processes \\
Organizational chart & Market segmentation \\
Accounting timely & Competitiveness (market positioning) \\
\hline
\end{tabular}

Table 2. Statistical values related to suitability of data for structure detection KMO and Bartlett's test

\begin{tabular}{lcc}
\hline Kaisser-Meyer-Olkin Measure of Sampling Adequacy. & .438 \\
\hline Bartlett's Test of Sphericity & Approx. Chi-Square & 679.982 \\
& df & 561 \\
& Sig. & .000 \\
\hline
\end{tabular}

Being so unpractical to handle 34 diagnostic basic elements, it was decided to obtain broader categories by using two data reduction methods: factor analysis and cluster analysis.

Factor analysis application found the sample as statistically unacceptable. The Kaiser Meyer Olkin (KMO) statistical value, by using the sample size as an indicator, was 0.438 . This value means that factor's frame resulting from the analysis would exhibit little stability in terms of repeatability and robustness. According to Morgan \& Griego (1998) the KMO should be greater than 0.70, and is inadequate if less than 0.50. KMO statistical value and its relation to its acceptance level are reported in Black (1993).

Bartlett's test of sphericity was significant (i.e., significance less than 0.05). Small values of the significance level indicate that a factor analysis may be useful with your data.

In considering that KMO test and Bartlett's test were opposite in meaning, authors decided not continue with factor analysis and attempt cluster analysis. Statistical values for factor analysis are given in table 2 . 
Two different procedures were used for the cluster analysis: k-means cluster analysis and hierarchical cluster analysis. Both procedures found the significance as statistically poor. Maximum distance (association) between case and cluster is bigger than minimum distance between final cluster centers $(2.68>1.498)$ (k-means cluster analysis). Association values from proximity matrix (hierarchical cluster analysis) were considered as low. Only two values were larger than 0.5.

Even though results from cluster analysis were statistically inadequate, authors consider that conceptual functionality of those diagnostic basic elements that were defined as initial centers in the cluster analysis was acceptable. It was decided to establish them as diagnostic categories. Diagnostic categories are given in table 3 .

Table 3. Diagnostic categories

Background of quality practices implementation

General assessment of production infrastructure

Abilities and attitudes of human capital

General assessment of competitiveness

General assessment of financial performance

Structure for objectives achievement

Processes documentation

Validity of categories is based on three analytical aspects. The exhaustive review on literature and consultation with experts, comparison of responses with perceived diagnostic elements of consultants and the degree to which each group of items was represented as a single construct in cluster analysis.

The success percentage distribution in quality practices implementation based on the diagnostic elements is shown in figure 1; 61 out of 65 consultants answered this issue. Survey answers showed up that more than 90 percent of the consultants had made successful implementations in most of the times (75\% to 100\%) when using the diagnostic elements.

Distribution of professional profile for the surveyed consultants is shown in figure 2 .

\section{Findings}

The consultant profile may summarized as specialized (60 percent are graduated) with an engineering education (74 percent) and wide experience (36.9 percent of

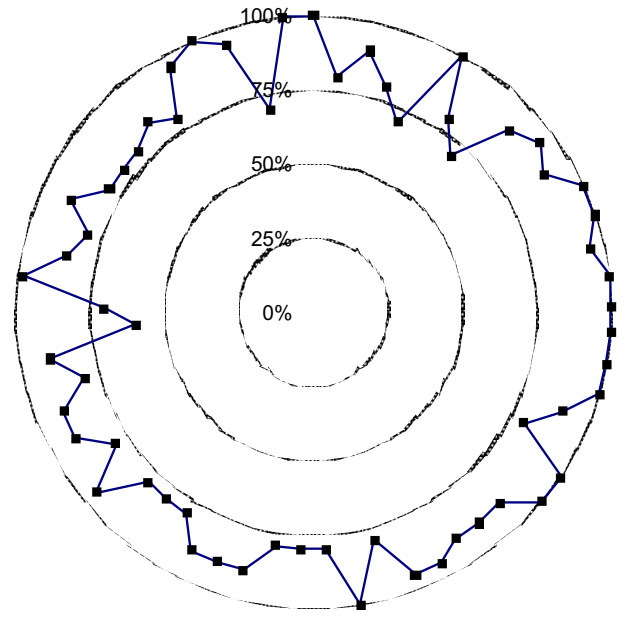

Figure 1. Percentage of success for a consultant in quality practices implementation

consultants have more than 10 years of experience) 71 percent of consultants obtained their experience in consultancy working for industrial MSMEs. Consultancy is a dominion for engineers. This fact has made engineers to get involved in management and organizational behavior. The low statistical significance obtained through the application of the data reduction methods implies diversity and independence of the diagnostic basic elements.

The use of diagnostic elements increases the success probability in the implementation of quality practices. To get an initial picture of organization, setting up the main problems, allows the consultant to make decisions about the kind of quality practice he needs to implement.

\section{Conclusions}

Even though it is possible to identify diagnostic basic elements, they tend to be diverse and differentiated. This is so, because consulting work is focused on the consultant rather than on the organizations. More over, due to the existence of several conceptual frames to formulate a diagnosis, there is no agreement among consultants on the way one should treat the same organizational problem. Additionally, quality movement has been globalized and is getting involved in a wide range of organizational activities.

The use of diagnostic elements increases the probability of success in the implementation of quality practices. 


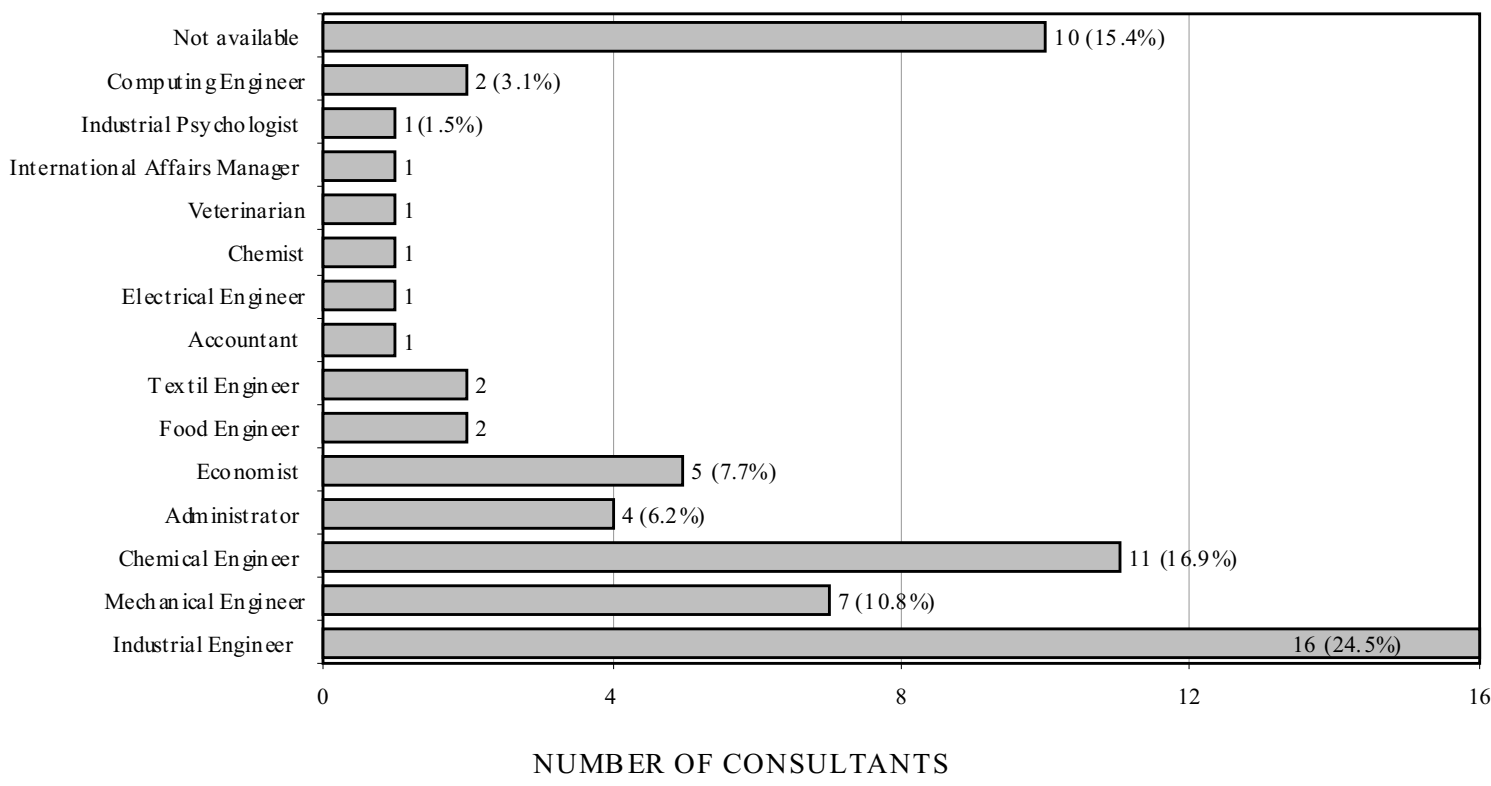

Figure 2. Distribution of professional profile of the surveyed consultants

Due to its broad nature, the diagnostic basic elements, as they were identified in this paper, independently of the type of organization on which they could be used, have a wide range of applications.

Grouping diagnostic basic elements with the use of statistical methods produced a poor level of significance. However, authors consider that categories proposed by themselves make sense conceptually.

Time and cost for the diagnosis stage should be considered. Time is a limited resource so the clients try to impose the shorter possible period for the diagnosis. Cost is an issue to negotiate. The client always has the last word, on how much he is willing to spend. Usually, the consultant has to adjust himself to time and cost constrants. They may propose implementation of cheaper and less complex quality practices that need shorter time to be set up.

Those elements in the organizational context that are perceived as potential obstacles for implementation should be pointed out from the beginning. Here we included: inadequate government policies and regulations, technological obsolescence emerge of substitute products and services, changes in consumption pattern, among others.

Both, implementation and diagnosis are complex processes in terms of the relationships they establish among the system components, beyond the complexity of the components themselves.
Because of the importance and complexity, implementation and diagnosis, should be studied in more detail that they have deserved up to now. Authors consider that implementation and diagnosis may be seen themselves as stages of the planning processes and in that sense they should be planned too. As any other planning problem should consider implementation and diagnosis integrated by three factors: (1) the subject, in this case the consultant, (2) the object to act on, in this case the organization and (3) the designer bias, in this case the consultant's view of the organization.

Finally, authors consider that the diagnostic basic elements and the categories identified may be considered of practical use in terms of being used for future research en the field of quality practices. A model of diagnosis for quality practice implementation may be developed by using the diagnostic basic elements and categories that were identified in this research.

\section{Acknowledgements}

The authors wish to acknowledge Álvaro Quijano-Solís for his helpful comments to the final version of this paper. 


\section{References}

Ahmadi M., Helms M.M. Is your TOM Program Successful? A Self Assessment Tool for Managers. The TQM Magazine, 7(2):52-56. 1995.

Bunney H.S., Dale B.G. The Implementation of Quality Management Tools and Techniques: a Study. The TQM Magazine, 9(3):183-189. 1997.

Black S.A. Measuring the Critical Factors of Total Quality Management. (Ph. D. thesis). U.K. University of Bradford, 1993.

Cámara Nacional de Empresas de Consultoría (CNEC) México. [on line] 2003. Available on: http://www.cnec.org.mx

Casadesús M., Giménez G. The Benefits of Implementation of the ISO 9000 Standard: Empirical Research in 288 Spanish Companies. The TQM Magazine, 12(6):432-441. 2000.

Dayton N.A. Total Quality Management Critical Success Factors, a Comparison: the UK Versus the USA. Total Quality Management, 12(3):293-298. 2001.

Dick G.P.M. ISO 9000 Certification beNefits, Reality or Myth? The TQM Magazine, 12(6): 365-371. 2000.

Easton G.S., Jarrell S.L. The Effects of Total Quality Management on Corporate Performance: An Empirical Investigation. Journal of Business, 71(2):253- 307. 1998.

Flynn B.B., Schroeder R.G., Sakakibara S. The Impact of Quality Management Practices on Performance and Competitive Advantage. Decision Sciences, 26 (5): 659-691. 1995.

Galperin B.L., Lituchy T.R. The Implementation of Total Quality Management in Canada and Mexico: a Case Study. International Business Review, 8:323-349. 1999.

Harrington J.H. The Fallacy of Universal Best Ppractices. The TQM Magazine, 9 (1):61-75. 1997.
Hendricks K.B., Singhal V.R. Does Implementing an Effective TOM Program Actually Improve Operating Performance? Empirical Evidence from Firms that have won Quality Awards. Management Science, 43(9):1258-1274. 1997.

Howard A. Associates Diagnosis for Organizational Change, Methods and Models. The Guilford Press. N.Y. 1994.

Internacional Labour Organisation Management Consulting, a Guide to the Profession. Second (revised) Edition. Edited by Milan Kubr. International Labour Organization. Geneva. 1986.

Mann R., Kehoe D. An Evaluation of the Effects of Quality Improvement Activities on Business Performance. International Journal of Quality \& Reliability Management, 11(4):29-44. 1994.

Morgan G.A., Griego O.V. Easy Use and Interpretation of SPSS for Windows: Answering Research Questions with Statistics. Mahwah. New Jersey. 1998.

Nacional Financiera (nafin), S.N.C. [on line] 2004. Available on: http://www.nafin.com

Nesbary D.K. Survey Research and the World Wide Web. Needham Heights. Massachusetts. Allyn and Bacon. 2000 .

Pitts C. Is it Spring or Autumn for TOM? The TQM Magazine, 6 (5):35-37. 1994.

Secretaría de Economía [on line] 2004. Available on: http://www.economia.gob.mx

Taiwo J. Systems Approaches to Total Quality Management. Total Quality Management, 12 (7-8):967-973. 2001.

Zairi M., Letza S.R., Oakland J.S. Does TOM Impact on Bottom Line Results. The TQM Magazine, 6 (1):38-43. 1994.

Zain Z.M., Dale B.G., Kehoe D.F. Doctoral TOM Research of Themes, Directions and Trends. Total Quality Management, 12 (5):599-609. 2001.

\footnotetext{
About the authors

Benito Sánchez-Lara. Received the Bachelor degree in Chemical Engineering. He holds the Master and Doctorate degree in the Engineering Program from the UNAM. Nowadays he is an Associate Professor in the Systems Engineering Department of UNAM where he is involved in Organizational and Transportation Systems Planning. His research interests include organizational diagnosis, quality practices implementation and viable systems analysis.

Gabriel De las Nieves Sánchez-Guerrero. He holds the Doctor degree (Hons.) in Systems Engineering from the Engineering School at the National Autonomous University of Mexico (UNAM). His current research interests include heuristic techniques for participatory planning, evaluation of projects and programs and processes brief intervention in organizations.
} 